\title{
श्रीमद्भागवत महापुराण में वर्णित सांगीतिक कला के तत्त्व
}

लायका भाटिया

संगीत विभाग, पंजाब विश्वविद्यालय, चण्डीगढ़

डॉ. अमिता शर्मा

अध्यक्ष, संगीत विभाग, पी.जी.जी.सी.जी, सैक्टर-11, चण्डीगढ़

भारतीय वाङ्मय में अष्टादश पुराणों का अपना विशेष स्थान रहा है किंतु श्रीमद्भगवत का विशिष्ट एवं अप्रतिम स्थान है। श्रीमद्भागवत धार्मिक, आध्यात्मिक, वाड्मय का सर्वश्रेष्ठ तथा समुज्जवल ग्रन्थ है इसे भक्ति, ज्ञान वैराग्य की आनन्दायिनी त्रिवेणी माना जा सकता है। श्रीमद्भागवत पुराण केवल आध्यात्मिक दृष्टि से ही महत्त्वपूर्ण नहीं अपितु कई विषयों को अपने में संजोए हुए है। इसमें ब्रह्माण्ड, सृष्टि, आख्यान, योग तथा कला आदि वर्णित विषय है। भागवत महापुराण कला की दृष्टि से अत्यन्त महत्त्वपूर्ण है। श्रीकृष्ण को चौंसठ कलाओं में निपुर्ण बताया गया है।

\section{"अहोरात्रौश्चतुः षष्ट्या संयतौ तावतीः कलाः \\ गुरुदक्षिणयाचार्य छन्दयामामतुर्नृप।।}

अर्थात् केवल चौसठ दिन-रात में ही संयमीशिरोमणि दोनों भाइयों ने चौसठ कलाओं का ज्ञान प्राप्त कर लिया। अध्ययन समाप्त होने पर उन्होंने सन्दिपनि मुनि से प्रार्थना की कि 'आपकी जो इच्छा हो, गुरू-दक्षिणा माँग लो।

\section{संगीत के विभिन्न तत्त्व}

श्रीमद्भागवत में संगीत की तीनों विद्याओं गायन, वादन तथा नृत्य का विवरण अनेक संदर्भों में प्राप्त होता है। भागवतीय साधना में भी संगीत का अत्यन्त महत्वपूर्ण स्थान था। यत्रा-तत्रा भक्ति साधना के अन्तर्गत कीर्तन का उपदेश किया गया है। इस प्रकार के कीर्तनों में संगीत के तीनों अंग अर्थात् गायन, वादन एवं नृत्य का प्रचलन था। गायन के अन्तर्गत स्वर, जाति एवं ध्रुव पारिभाषिक शब्दों का भी उल्लेख प्राप्त होता है। स्वरों की संख्या सात ही बताई गई है। इन सातों स्वरों की उत्पत्ति बह्मा से मानी गई है। गायन कला उस समय भी लोकप्रिय कला थी। कृष्ण एवं बलराम को श्रेष्ठ गायक बताया गया है। सूत, मागध एवं वन्दी उस समय संगीतोपजीवी लोग होते थे। सूत पुराण आदि की कथा का वाचन करते थे। मागध एवं वन्दीजन राजाओं आदि की स्तुति गाने वाले होते थे एवं गन्धर्व शब्द श्रेष्ठ गायक कलाकारों के लिए प्रयोग किया जाता था। गीत गोष्ठियों का भी भागवत पुराण में उल्लेख प्राप्त होता है। जातकोत्सव आदि पारिवारिक उत्सवों के अवसर पर स्त्रियाँ गायन करती थी।

\section{वादन कला का पुट}

भागवत पुराण में कई प्रसंगों में वादन का भी उल्लेख प्राप्त होता है। इसके श्लोकों में वाद्यों का अद्भुत वर्णन है। वाद्यों की ध्वनि द्वारा भावों के चित्रण में भागवत अद्वितीय काव्य है। कृष्ण स्वयं वेणु वादन में प्रवीण थे। श्रीमद्भागवत पुराण में वंशीध्वनि श्रीभगवान् की रासलीला की प्राथमिक अभिव्यक्ति है। सम्पूर्ण रासलीला का यह मूल सूत्र है। 
वेणुगीत में 'वेणु' का बहुत ही मधुरम प्रभाव देखा जा सकता है है। वेदों में भगवान के दो स्वरूप बतलाए गये है- नाम और रूप। वेणुगीत भगवान् के नामात्मक स्वरूप का बोध कराता है। 'वेणु' शब्द में 'व', 'इ' और 'अणु' ये तीन शब्द है। 'व' का अर्थ है ब्रह्म का सुख, 'इ' का अर्थ है काम का सुख और 'अणु' यानी तुच्छ अर्थात् जिस सुख के सामने सांसारिक तथा आध्यात्मिक सुख अणु यानी तुच्छ हो जाते हैं उसे ही वेणु कहते हैं। यह सुख, यह भगवप्रेम जीवों को अपने-अपने साधन से नहीं मिलता, भगवान के अनुग्रह से ही मिलता है। भगवान् वेणु बजाकर स्नेह रूप सुधा की वर्षा करते है।

गायन गोष्ठियों की भांति ही वादित्रगोष्ठियों का भी उस समय आयोजन किया जाता था। धार्मिक एवं पारिवारिक उत्सवों के अवसर पर अनेक वाद्य बजाये जाते थे। भागवत पुराण में निम्नलिखित वाद्यों का उल्लेख प्राप्त होता है- आनक, गोमुख, घण्टा, तूर्य, दुन्दुभि, धुन्धुरी, पणव, पटह, भेरी, मुरज, मृदंग, वीणा, वेणु, श्रृंग, शंख इत्यादि।

\section{नृत्य तथा नाट्यकला से सम्बद्ध}

नृत्य कला का भी कई स्थलों पर उल्लेख प्राप्त होता है। कीर्तनों के अवसर पर भी नृत्य का प्रचलन था। कालिया नाग पर नृत्य करते हुए कृष्ण को अखिल कलादिगुरू अभिहित किया जाता है। स्त्री एवं पुरूष दोनों में ही नृत्य का प्रचलन था। अनेक अवसर पर वारांगनाओं द्वारा भी नृत्य किया जाता था।

रास नृत्य का भी विशेष विवरण प्राप्त होता है। रास मुलतः नृत्त है। नृत्त-ताल आश्रित होता है। पदार्थाभिनय एवं भावाश्रय होने से नृत्त, नृत्य बन जाता है। रास-नृत्य आज भी रासलीला का एक महत्त्वपूर्ण अंग है। रास-चाहे उपरूपक हो, नाट्य हो अथवा गेयरूप-सभी में रास-नृत्त का महत्त्व अनिवार्य रहा है। केवल परवर्ती जैन-परम्पराओं ने अपनी तत्कालीन स्थितियों और उपदेश की मनोवृत्ति के कारण रास के नृत्त-रूप पर प्रतिबन्ध लगाया था, इससे उनकी 'रासक' रचनाएँ नाटय के स्थान पर मात्र काव्यरूप बन कर रह गई।

\section{हल्लीसक तथा रास}

'हल्लीसक' को रास का पूर्व रूप बताया गया है तथा उसका सहचर भी। अधिकर लक्षणग्रनथ 'रास' और 'हल्लीसक' को एक मानकर चलते हैं। हल्लीसक नृत्य का वर्णन भास के बालचरित में आया है। यहाँ एक प्रसंग के अनुसार श्रीकृष्ण ने कालिया के फ़नों पर हल्लीसक नृत्य किया है। इस वर्णन से हल्लीसक नृत्य की किसी रूपरेखा का निर्धारण नहीं होता। इसी ग्रन्थ के तृतीय अंग में गोप और गोपियों के साथ सम्पन्न श्रीकृष्ण के हल्लीसक नृत्य का वर्णन भी उपलब्ध है। इस सन्दर्भ से यह सिद्ध होता है कि हल्लीसक स्त्री-पुरूषों का एक मण्डलाकार समूह नृत्य था, जो विविध ताल, लय एवं गायन-वादन से समन्वित था।

\section{रास-दर्शनपरक अभिव्यक्ति}

आरम्भ से ही रासनृत्य और लील का सम्बन्ध श्रीकृष्ण से रहा है। अतः भगवत्स्वरूप श्रीकृष्ण के उपासकों के मध्य रासलीला की अनेक दर्शनपरक व्याख्याएँ भी होती रही हैं। 'रास' शब्द का 'रस' शब्द से सीधा सम्बन्ध है। 'रस' स्वयं श्रीकृष्णस्वरूप है, ऐसा गीता में कहा गया है। उपनिषदों में 'रसो 
वै स:' द्वारा जिस ब्रह्म का अभिधान किया गया है, वह परब््म्म श्रीकृष्ण ही है। 'रसानां समूहों रास': में रास को सर्वरसमयता को स्पष्ट किया गया है। जितने भी रस है, उन सबका समूह रास है।

छलिक (छालिक्य) और रास

'छलिक' अपनी स्वरूप-विधा में एक अभिनय प्रकार है, जिसको कोशग्रन्थों में गान-भेद एवं रूपक-भेद माना गया है। हरिवंश पुराण में इसे बहुसन्निधान में हुआ एक गेय गन्धर्व बताया गया है। गान्धर्व में पद-वस्तु स्वततालानुभावित होती है। हरिवंश का छालिक्यवर्णन स्वरतालानुरूप पदों की गेयात्मकता एवं आसारित आदि क्रियाओं से युक्त अभिनयत्व की समुचित व्यवस्था का उद्घाटन करता है। यहाँ नारद षट्ग्राम वीणा बजाते हैं, वंशीवादक श्रीकृष्ण हल्लीसक नृत्य का प्रदर्शन करते हैं, अर्जुन मृदंग एवं अन्य अप्सराएँ नानाविध वाद्य समायोजित करती हैं।

छलिक की उत्पत्ति एवं परंपरा से सम्बद्धित एक विवरण छान्दोग्य उपनिषद में भी प्राप्त है। इसके अुनसार महर्षि अंगीरस से सामगान की शिक्षा प्राप्त कर श्रीकृष्ण ने छलिक नामक इस गानविधि को गोपियों के साथ नृत्य में प्रयुक्त किया गया है।

नाट्यकला का भागवतपुराण में कई स्थलों पर उल्लेख प्राप्त होता है। यद्यपि किसी प्रसंग में नाट के अभिनीत किये जाने का उल्लेख नहीं प्राप्त होता है। तथापि नट, नाट्य, एवं जवनिका, शब्दों का कई सथलों पर भागवतपुराण में उल्लेख प्राप्त होता हे। भागवत में भगवान् की लीलाओं की तुलना नटचर्या से की गयी है। अन्यत्रा कृष्ण व बलराम की तुलना रंगभूमि में गाते हुए नट से की गई है।

छलिक के अतिरिक्त चर्चरी तथा फागु आदि गेय विधाओं का सम्बन्ध रास से जोड़ा गया है। अतः नृत्त, नृत्य, गान, अभिनय आदि विभिन्न तत्त्वों एवं हल्लीसक, चर्चरी, फ़ागु और छलिक आदि रास के विभिन्न अंग हैं। रासलीला के अतिरिक्त भगवान पुराण में नृत्य की किसी और शैली का उल्लेख प्राप्त नहीं होता है।

\section{संदर्भ ग्रन्थ सूची}

1 श्रीमद्भगवत पुराण, गीताप्रेस गोरखपुर, $8 / 21 / 7$

2 वही, $10 / 33 / 10$

3 वही, $3 / 12 / 47$

4 वही, $10 / 21 / 8$

5 वही, $1 / 10 / 20$

6 वही, $11 / 11 / 36$

7 वही, $10 / 7 / 4,10 / 5 / 12-14$

8 वही, $10 / 18 / 13$

9 वही, $1 / 10 / 5,10 / 71 / 14,10 / 71 / 19-30$

10 वही, $1 / 10 / 15$

11 वही, $10 / 50 / 38$

12 वही, $10 / 50 / 30,8 / 21 / 7$

13 वही, $4 / 24 / 23-24,18 / 17 / 30$ 
14 वही, $10 / 71 / 14$,

15 वही, $10 / 71 / 30$

16 वही, $10 / 70 / 20,1 / 10 / 15$

17 वही, $10 / 12 / 27,10 / 11 / 39$

18 वही, $10 / 11 / 1$

19 वही, $1 / 10 / 5$

20 वही, $8 / 21 / 7$

21 वही, $10 / 16 / 26$

22 वही, $10 / 41 / 1$

23 वही, $1 / 9 / 19$

24 वही, $1 / 3 / 37$

25 वही, $10 / 21 / 8,10 / 43 / 19$

26 'भावाश्रयं नृत्यम्'- दशरूपक $1 / 9$, धनजय

27 अभ्जिनयदर्पण, श्लोक 16, ननिछकेश्वर

28 बालचरितम् $4 / 6$, भास

29 वही, पृ० $43-44$ तथा 47

30 वाचस्पत्यम् (बृहत् संस्कृताभिधानम) चतुर्थभाग पृ० 2998

31 भारतीय नाट्य-परम्परा और अभिनयदपूर्ण पृ० 140, वाचस्पति गैरोला 